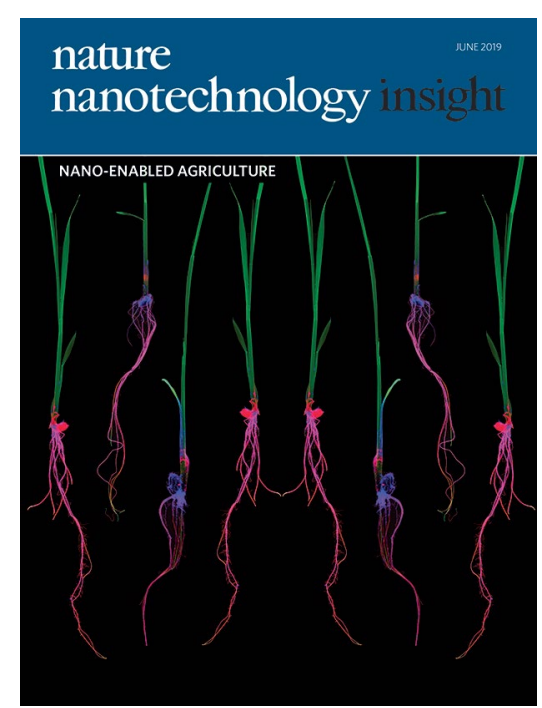

Image: Eleanor Spielman-Sun and Astrid Avellan, Carnegie Mellon University Cover Design: Bethany Vukomanovic

\section{SPRINGER NATURE LONDON \\ The Campus, 4 Crinan Street, \\ London N19XW \\ T: +442078334000 \\ F: +442078434563 \\ nano@nature.com \\ CHIEF EDITOR \\ FABIO PULIZZI}

INSIGHTEDITOR

FABIO PULIZZI

SENIOR PRODUCTION EDITOR

KARL SMART

COPY EDITOR

TIM BODICOAT

ART EDITOR

TULSI VORALIA

EDITORIAL ASSISTANT

KATHERINE GROVES

EDITORIAL DIRECTOR

ALISON WRIGHT

EDITOR-IN-CHIEF,

NATURE PUBLICATIONS

MAGDALENA SKIPPER

\title{
Nano in the future of crops
}

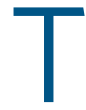
he first thing we read on the webpage of the 'Zero hunger' Sustainable Development Goal of the United Nations is that the number of undernourished people has roughly halved in the past 20 years. However, this perhaps surprising piece of good news is followed immediately by the notion that almost a billion people still live in conditions of insufficient nutrition. There is more. The increasing population, as well as changes in the environment and higher demands of energy and water, are bound to put increasing stress on food production and distribution.

Achieving provision of food for the world population requires efforts of different types, including changes in behaviour, reduction of waste, increased preservation and international intervention, to name just a few. Arguably, however, it all starts with food production, which should increase in a sustainable fashion - that is, without putting extra strain on the environment and on energy demands.

We have reason to believe that nanomaterials could play an important role in the future of agriculture, especially in the production of crops, and the articles included in this Insight illustrate some of the most important opportunities of nanotechnology in smarter food production and preservation, as well as the challenges in technology and those posed by public perception and the lack of proper regulation.

Nano-enabled agriculture is still in its infancy but it is an exciting and challenging area that will develop fast in the near future, especially if the right emphasis is given to understanding the fundamental interactions between engineered nanomaterials and plants.

Fabio Pulizzi, Chief Editor

Published online: 5 June 2019

https://doi.org/10.1038/s41565-019-0475-1

\section{COMMENTS}

Moving policy and regulation forward for nanotechnology applications in agriculture

Neena Mitter and Karen Hussey p508

On the elusive nature of the public Koen Beumer

p510

How nanocarriers delivering cargos in plants can change the GMO landscape

Markita P. Landry and Neena Mitter

Q\&A

Expectations from nano in agriculture

Anne Mullen

\section{PERSPECTIVES}

Opportunities and challenges for nanotechnology in the agri-tech revolution

Gregory V. Lowry, Astrid Avellan and Leanne M. Gilbertson p517

A One Health approach to managing the applications and implications of nanotechnologies in agriculture

Enzo Lombi, Erica Donner, Maria Dusinska and

Fern Wickson

\section{REVIEW ARTICLES}

Nano-enabled strategies to enhance crop nutrition and protection

Melanie Kah, Nathalie Tufenkji and Jason C. White

Nanobiotechnology approaches for engineering smart plant sensors

Juan Pablo Giraldo, Honghong Wu, Gregory Michael Newkirk and Sebastian Kruss 